\title{
A Competência Legislativa Originária do Presidente da República
}

\author{
CLENÍCIO DA SILVA DUARTE
}

Consultor Jurídico do DASP

\begin{abstract}
SUMÁRIO : 1. A teoria clássica da separação de poderes e o seu papel histórico na democracia. 2. A evolução tecnológica e sua influência na Ciência Política. Conseqüente abrandamento do princípio da separação rígida de poderes. 3. Incapacidade material dos Parlamentos em acompanhar a evolução tecnológica. 4. A acentuada intervenção estatal no domínio econômico como uma das causas da necessidade de dinamismo da função legislativa. 5. A Legislação técnica e sua possibilidade de melhor elaboração na área do Executivo. 6. Necessidade de pronta reforma do Poder Legislativo. 7. A formulação do princípio da separação de poderes na Constituição em vigor e as ressalvas que se the introduziram. 8. A competência legislativa originária do Presidente da República. Casos em que se verifica. 9. Competência para baixar decretos-leis. Condições de seu exercício. 10. Natureza jurídica do decreto-lei. Sua equivalência, no que concerne à eficácia, à lei ordinária. 11. Suporte fático conferidor da competência de baixar decretos-leis. 12. A rejeição do decreto-lei pelo Congresso. Efeitos da desconstituição de eficácia. 13. A origem do decreto-lei tal como previsto na Constituição. 14. Exame dos pressupostos da competência legislativa originária expressa. 15. A condição de não aumentar a despesa pública. Inteligência da expressão. 16. Matérias sobre que pode versar o decreto-lei. 17. Segurança nacional - seu conceito na jurisprudência. 18. Direito financeiro e normas tributárias. Estaria, nessa competência, incluída a de criar e aumentar tributos? 19. Criação de cargos públicos e fixação de vencimentos. Âmbito de incidência. 20. Conclusão.
\end{abstract}

com 1. Se é inegável que a teoria da separação de poderes, com o seu sistema de freios e contrapesos, tal como a formulara 
MONTESQUIEU11, contribuiu extraordinariamente para a formação do Estado Democrático, não é menos exato que essa separação rígida não teria condições de manter a dinâmica de governo após toda a evolução da Ciência Política, que não poderia desacompanhar o surpreendente progresso da tecnologia ${ }^{2}$, que se seguiu a este após-guerra, quando passou a predominar a sociedade industrial de nossos dias ${ }^{3}$.

2. Esse extraordinário surto tecnológico encontrou totalmente despreparados os Parlamentos, que assim se viram inca-

\section{Cf. L'Esprit des Lois, Livro XI, Capítulo VI.}

A preocupação de Montesquieu, que se inspirara na organização constitucional decorrente da Revolução Inglesa de 1688, era evidentemente (embora, por motivos óbvios, procurasse contestá-la no Prefácio), a de combater o absolutismo reinante em sua pátria e difundido no continente, com o que contribuiu de modo eficaz para o desencadeamento das idéias que facilitaram a Revolução Francesa. O embriăo da teoria poderia ser encontrado na Política de ARIS. TOTELES, e LOCKE (The Second Treatise of Government, publicado em 1690), como teórico da Revolução Inglesa e difusor das idéias que inspiraram a Revolução Norte-americana de 1776, também já a havia formulado, ainda que não tão claramente como o notável escritor francês. Assim é que se refere à separação dos poderes legislativo e executivo-federativo (capit. XII), com prevalência do primeiro, que seria o poder supremo, desconhecendo o judiciário. 0 poder que chama federativo desenvolvia um conjunto de funções que competem hoje ao executivo com autorização do legislativo, tais como declarar a guerra e fazer a paz, firmar tratados, convenções e outros atos internacionais (Cf. Const. Fed. art. 44, n. ${ }^{\circ} \mathrm{s} I$ e II).

Note-se que, como adverte JOHN HAZARD, A Regra da Legalidade nos Paises do Oriente, in Revue Internationale de Droit Comparé, 1958, p. 78, "a India conheceu o princípio da separação de poderes muito antes de Montesquieu, pois os reis pediam aos juristas para lhes ensinar o direito e os juristas que interpretavam a lei não estavam necessariamente a serviço dos reis. Esta tradição se perpetuou até os tempos modernos com Ghandi e os outros profetas que o povo respeita."

2. Cf. nossos artigos sob os títulos: A Concepção Moderna de Democracia e o Primado do Direito Administrativo (nesta Revista, vol. 99, n.os 3 e 4, julho a dezembro de 1967, ps. 68 e segs., e na Revista de Direito Público, vol. 5, ps. 202 e segs.); Os Regulamentos Independentes (nesta Revista, vol 105, n. 2, maio a agosto de 1970, ps. 31 e segs., e na Revista de Direito Público, vol. 16, ps. 89 e segs.); A Unificação de Princípios na Constituição Federal de 1967 (id., vol. 107, n.० 1, janeiro a abril de 1972, ps. 23 e segs.), e Delegação de Competência (id, vol. 108, n. ${ }^{\circ}$, janeiro a abril de 1973, ps. 53 e segs.)

3. Vejam, a propósito, as seguintes palavras de FORSTHOFF, na conferência que o eminente mestre de Heidelberg proferiu em junho de 1963, perante a Sociedade de Juristas de Berlim, sob o título Strukturwandlungen der modernen Demokratie (Transformações Estruturais da Democracia Moderna), Berlim, 1964, p. 16: "A sociedade industrial moderna, em sua complexidade e na plenitude de suas interdependências, coloca o Estado diante de tarefas que nåo seriam solucionadas por manifestaçōes de vontade no velho estilo. Para sua realizaçấo não se recorre a decisōes políticas, mas de natureza técnica. Essa decisăo técnica muitas vezes nada mais é do que a resultante adequada (ermittelnde Resultante) para uma comple. xa situação de fato. Daí a razăo pela qual o técnico cada vez mais participa da execuçăo das atividades estatais". 
pacitados de acompanhar essa evolução4. Por esse efeito, tiveram de sofrer considerável capitis diminutio em sua atividade principal, lançando mão, em favor do Executivo, ora das delegações legislativas, ora tendo de permitir o exercício da função legislativa originária concomitantemente com este.

A rigidez da teoria da separação de poderes como a conceituara MONTESQUIEU, que só admitia a interferência do Executivo no processo de formação legislativa através do veto (faculté d'empêcher) já sofrera restrições, com a atribuição confe-
rida ao Executivo na iniciativa de leis, primeiro concorrentemente e, depois, privativamente, com exclusão assim, em certas matérias, da própria competência do Legislativo, acentuando-se, de modo quase revolucionário, como fenômeno universal nos Estados democráticos modernos, pela delegação legislativa, disfarçana feitura de atos legislativos. 3. Essa evolução se deu, como se disse, por força da
incapacidade material em que ficaram os Parlamentos de acompanhar a dinâmica assustadora da sociedade moderna, dominada pela tecnologia, que torna avelhantadas fórmulas de ontem, numa febril transformação de métodos e de conceitos, o que só poderia ser seguido pela gigantesca máquina à disposição do Executivo, com toda a sua aparelhagem eletrônica, sendo impraticável, por motivos óbvios, a mesma assessoria para o Legislativo. Também, sob o aspecto democrático, não há perda de conteúdo, porque é preciso não esquecer que, ao monarca absoluto, de direito divino, que inspirara a necessidade da teoria separatista, substituiu-se o Chefe de Estado de origem popular, eleito por sufrágio direto ou indireto, o que não permite a desconfiança que então se justificava. ${ }^{5}$

ria Nem seria lícito pretender a manutenção lírica de uma teoma que teve o seu extraordinário valor para o momento histórico, na não poderia ser perfilhada atualmente com ortodoxia, sob petã de se negar a evidência de uma metamorfose social e política tão profunda que jamais seria então sequer suspeitada. Se as ciências naturais, já de si muito mais estáticas, sofreram total re-

\footnotetext{
4. Cf. excelente resumo do fenômeno feito por MANUEL GONÇALVES FERREIRA FILHO in Do Processo Legislativo. Saraiva, S. Paulo, 1968, n.ㅇs 72 segs. Veja-se, também, a magnifica conferência de FORSTHOFF, citada na nota anterior.

Cf. MANOEL GONÇALVES FERREIRA FILHO, ob. cit., n.॰ 74
}

R. Serv. públ., Brasília, 109 (2) abr./jun. 1974 
visão de conceitos, como não admitir a evolução das ciências sociais, que, além de condicionadas àquelas, também têm o seu próprio e constante devenir?

4. A acentuada intervenção estatal no domínio econômico, quando se entendeu que a Ciência Econômica não tinha condições de atuar independentemente, passando-se do laissez faire, laissez passez para o condicionamento legal do fenômeno econômico, exigiu uma verdadeira hipertrofia da função legislativa, impondo-se uma maior celeridade ao processo de formação da norma jurídica. E os Parlamentares não tinham como atender a essa demanda de leis, a serem rapidamente elaboradas e em quantidade efetivamente além de toda e qualquer possibilidade material de atendimento, pela natural morosidade da elaboração legislativa nas assembléias populares.

5. Em muitos casos, também, dada a natureza da matéria, o Executivo tem melhores condições de elaborar a norma jurídica, com o que não se fere a harmonia e independência dos Poderes, desde que se concedam às assembléias legislativas meios de fiscalizar essa atividade legisferante. Se a principal função conferida aos Parlamentos no Direito moderno passou a ser a legislativa, não se deve esquecer que sua atividade originária era eminentemente controladora do Executivo, só mais tarde se lhe conferindo função de editar o direito positivo ${ }^{6}$.

6. A reforma pronta e imediata do Legislativo, que não mais pode ser retardada, sob pena de se comprometer definitivamente o regime democrático, terá de romper com preconceitos, num trabalho sério e corajoso, voltado para as raízes da instituição, que ou se atualiza com realismo, ou se tornará um órgão ineficiente e desprestigiado.

Se o Executivo sofreu transformações profundas, inclusive sob o aspecto de se Ihe permitir, no Estado mais democrático que se possa imaginar, a invasão de competência que, até bem pouco tempo, só era deferida ao Legislativo, e não há oûtra solução sem que se emperre a atividade governamental, por que não se há de reconhecer a necessidade de reforma profunda $e$ substancial do Legislativo? Se é pacífica a necessidade de se conferir ao Executivo uma maior participação direta no processo legislativo, como não aceitar-se a correspondente perda de com-

6. Veja-se aut. e ob. cits. na nota anterior, n. $\circ 178$

R. Serv. públ., Brasília, 109 (2) abr./jun. 1974 
petência do Legislativo, quando a atuação de um evidentemente Só se fará em prejuizo da atividade do outro? Nessa reforma, se se atender à realidade da Ciência Política moderna, não haverá qualquer desprestígio para os Parlamentos, desde que, em troca da atividade legislativa que possam perder em extensão e profundidade, poder-se-á conferir-lhes uma eficiente e verdadeira ação fiscalizadora, que só nominalmente a possuem na atualidade.

Que adianta, por exemplo, consignar ao Poder Legislativo competência constitucional para deliberar sobre o orçamento da União, votando a lei de meios, se não pode apresentar "emenda de que decorra aumento de despesa global ou de cada órgão, fundo, projeto ou programa, ou que vise a modificar-lhe o montante, a natureza ou o objetivo ${ }^{7 "}$, nem se lhe confere a faculdade de rejeitar o projeto $^{8}$ ? Que modificação de relevância poderia o Legislativo produzir em tal projeto, que justificasse essa competência? Não seria muito mais lógico e racional, - além da extraordinária redução de despesa que representaria, com a desnecessidade de sessões e mais sessões extraordinárias para atender, na votação, aos prazos constitucionais, - que a Constituição atribuísse ao Presidente da República a competência de baixar o orçamento por ato seu, conferindo ao Poder Legislativo uma maior atribuição fiscalizadora da execução orçamentária? Que contribuição estaria o Legislativo em condições de oferecer à elaboração orçamentária, quando o Executivo é que, de fato, sabe do que necessita para atender ao seu programa de governo? Estabelecido o programa e os recursos para custeá-lo, caberia tão-somente ao Legislativo verificar o cumprimento desse programa e o bam emprego das dotações consignadas, segundo os itens em que se distribuiram. Enquanto isso, reservar-se-ia ao Legislativo muito mais tempo para tarefas em que, realmente, pode apresentar contribuição de valia. Mas os tabus são difíceis de Ser vencidos e muitas vezes se prefere agarrar-se a uma tradição obsoleta do que enfrentar-se a realidade, quando é muito mais prestigioso para um órgão restringir-lhe a competência, mas respeitá-lo nela, do que alargarem-se-lhe as atribuições que são exercidas apenas nominalmente.

7. O princípio da separação de poderes se acha formuado no art. 6..$^{\circ}$ e seu parágrafo único da atual Carta Política da

\footnotetext{
7. Constituição Federal, art. $65, \S 1 . \circ$

8. Id., art. 66, caput, in fine.

Cf. Interpretação que demos ao dispositivo in parecer publicado na Revista de Direito Público, vol. 10 , ps. 278 e 279
} 
União, que estabelece a independência entre eles, ainda que devam funcionar harmonicamente, só se admitiu ressalvas à vedação de delegar atribuições e do exercício da função de um por quem esteja investido na de outro, quando previstas na Constituição.

Pela primeira vez no nosso Direito Constitucional legislado, com exceção evidentemente da Carta de 1937, de inspiração totalitária, em que desaparecera o Congresso Nacional, acumulando-se nas mãos do Diretor as funções executivas e legislativas, outorga-se a possibilidade de delegação de competência, quer dentro do mesmo poder, quer de um para outro, bem como a atribuição originária e derivada de competência legislativa ao Presidente da República ${ }^{9}$.

8. Como a atividade legislativa conferida ao Presidente da República, de maneira originária, pela Constituição Federal, é que constitui o objeto deste trabalho, não consideraremos aqui a função, também legislativa, mas derivada, consistente na faculdade de elaboração de leis delegadas ${ }^{10}$.

A atividade legislativa originária do Presidente da República, se só ocorre, expressa e claramente, pela expedição de decretos-leis ${ }^{11}$, na realidade é muito mais ampla do que se possa, à primeira vista, imaginar. Assim é que, efetivamente, em mais duas hipóteses ela, na prática, se exerce : a) quando o projeto-delei de iniciativa ${ }^{12}$ do Presidente da República sobre qualquer matéria, exceto se se tratar de codificação ${ }^{13}$, é submetido ao Congresso Nacional, com solicitação de prazo $^{14}$, e dentro dele não delibera o Legislativo, caso em que é considerado aprovado, passando a vigorar como lei o projeto apresentado pelo Chefe do Go-

9. Cf. nosso artigo intitulado Delegação de Competência, cit. na nota 2, supra, in fine, in Rev.. vol. e número cits., p. 62 .

10. Cf. Const. Federal, arts. $46, n . \circ$ IV, 52 e 54

11. Id., arts. $46, \mathrm{n} .{ }^{\circ} \mathrm{V}$, e 55 .

12. A iniciativa, que é uma fase preliminar do processo de formaçăo da lei, quando oriunda do Presidente da República, tem excepcional importância, não só por não permitir, nos casos de competência reservada do Chefe do Estado, emendas que aumentem a despesa prevista (Const., art. 57, parágrafo único, alínea a), como, mesmo nas hipóteses de matérias de iniciativa concorrente, quando, solicitado prazo de deliberaçăo (Const., art. 51 caput, e $\S 2 .^{\circ}$ ) o Congresso năo delibera dentro dele.

13. Const., art. $51, \S 6 .^{\circ}$.

14. Id., art. 51 , caput, e $\S 2 .^{\circ}$

R. Serv. públ., Brasília, 109 (2) abr./jun. 1974 
verno 15 , o que significa a elaboração de uma lei sem qualquer colaboração ativa do Legislativo; b) no caso de projeto de lei orçamentária, quando não há, na prática, possibilidade de alterações substanciais ${ }^{16}$, e nem pode ser rejeitado o projeto. ${ }^{17}$

9. A competência legislativa conferida ao Presidente da República de maneira expressa, através de decreto-lei, é dependente da aprovação implícita ou explícita do Congresso Nacional e se limita quanto à matéria objeto de disciplinação e no que concerne às condições de exercício dessa faculdade.

Estabelecida pela primeira vez na redação primitiva da Constituição de 1967 , no seu art. 58 , sofreu algumas alterações pela Emenda Constitucional n..$^{1}$, de 1969 , consoante se verifica do seu art. 55. Assim, substituiu-se a expressão "decretos com força de lei" por "decretos-leis", estabeleceu-se mais uma matéria: "criação de cargos públicos e fixação de vencimentos", acrescentando-se, no n. ॥ I - "finanças públicas", a expressão: "inclusive normas tributárias". Também se dispôs, com a intro¿ução de um parágrafo (§ $\left.2 .^{\circ}\right)$, que "a rejeição do decreto-lei não implicará a nulidade dos atos praticados durante a sua vigência ${ }^{18 "}$.

10. Os decretos-leis são atos materialmente legislativos, equiparando-se, de maneira absoluta, uma vez aprovados tácita (decurso do prazo de sessenta dias sem deliberação - art. 55 ,

\footnotetext{
15. Id., art. $51, \S 30^{\circ}$.

16. Id., art. $65, \S 1 . \circ$

17. Id. art. 66 , caput, in fine.

18. Para se ter uma melhor idéia das alterações introduzidas, cotejemos os dois dispositivos, o primitivo e o atual. Assim, preceituava a redaçăo original da Constituiçăo de 1967: "Art. 58. O Presidente da República, em casos de urgência ou de interesse público relevante, e desde que năo resulte aumento de despesa, poderá expedir decretos com força de lei sobre as seguintes matérias : I - segurança nacional; II - finanças públicas. Parágrafo único. Publicado o texto, que terá vigência imediata, o Congresso Nacional aprovará ou rejeitará, dentro de sessenta dias, não podendo emendá-lo; se, nesse prazo, não houver deliberação, o texto será tido como aprovado". A redaçăo em vigor estatui : "Art. 55. O Presidente da República, em casos de urgência ou de interesse público relevante, e desde que não haja aumento de despesa, poderá expedir decretos-leis sobre as seguintes matérias: I - segurança nacional; II - finanças públicas, inclusive normas tributárias; e III - criação de cargos públicos e fixaçăo de vencimentos. § 1.० Publicado o texto, que terá vigência imediata, o Congresso Nacional o aprovará ou rejeitará, dentro de sessenta dias, năo podendo emendá-lo, se, nesse prazo, não houver deliberaçăo, o texto será tído por aprovado. $\S 2 .^{\circ}$ A rejeição do decreto-lei năo implicará a nulidade dos atos praticados durante a sua vigência" (grifaram-se as alteraçōes).
} 
$\left.\S 1 .^{\circ}\right)$ ou expressamente, às leis ordinárias, sem que sofram qualquer diminuição hierárquica em relação a elas.

Ao contrário do que sustenta o eminente Prof. GERALDO ATALIBA ${ }^{19}$, não nos parece que a excepcionalidade da autorização, a limitação das matérias sobre que podem versar, o processo de elaboração, os pressupostos e a condição de não resultar aumento de despesa, bem como a de se sujeitarem à aprovação do Congresso Nacional retiram deles a natureza de equivalência ao ato formal e materialmente legislativo. Se Ihe servem de distinção, porque, evidentemente, são atos diversos quanto a esses aspectos, não se diferenciam da lei ordinária, quanto à eficácia, após a plenitude de sua vigência.

11. A urgência e o interesse público relevante, que justificam a excepcionalidade da autorização, constituem o suporte fático conferidor da competência, mas não interferem na natureza do ato, porque the são anteriores. Vale dizer, se existem os pressupostos de urgência e de interesse público relevante, há autorização para baixar o ato sobre determinada matéria e sob certas condições, mas o ato baixado, porque verificados os pressupostos da competência excepcional, tem força de lei, tal como se passasse por um processo legislativo normal.

A limitação das matérias sobre que pode dispor também não influi na natureza do ato, depois de constituído. Com efeito, muitas matérias estão vedadas à iniciativa do Poder Legislativo, porque reservadas exclusivamente ao Presidente da República ${ }^{20}$, e, no entanto, não seriam menos leis por essa circunstância. Esses fatos apenas impedem a instauração do processo legislativo e, portanto, Ihe são anteriores, mas, uma vez verificados, e iniciado o processo legislativo, não há distinção de eficácia da lei, com vistas ao momento de deposição do projeto ou à natureza da matéria que pode disciplinar. De igual modo, as leis delegadas não podem disciplinar certas matérias ${ }^{21}$, mas, quando a delegação é feita ao Presidente da República, assim como o decreto-lei, só se distinguem das leis ordinárias pelo órgão de que emanam, conservando a mesma eficácia e hinarquia destas.

19. GERALDO ATALIBA. O Decreto-lei na Constituiçăo de 1967, Revista dos Tribunais, S. Paulo. 1967, ps. 16 a 40.

20. Constituiçăo Federal, art. 57.

21. Id. art. 52, parágrafo único.

R. Serv. públ., Brasília, 109 (2) abr./jun. 1974 
A condição de não aumentar a despesa também é irrelevante na distinção, porque a atuação legislativa do Congresso, quando está impedido de apresentar emenda que aumente a despesa prevista no projeto, nos casos das alíneas a e b do parágrafo único do art. 57, não diminui em nada a eficácia do ato legislativo que vier a ser aprovado, não servindo igualmente de distinção entre o decreto-lei e a lei ordinária, embora seja, lá como aqui, uma condição a ser respeitada por ambos os atos.

A condição de permanência de eficácia, concernente na aprovação tácita (pelo decurso do prazo sem deliberação do Congresso Nacional) ou expressa do decreto-lei baixado, do mesmo modo não serve de distinção, visto que a lei delegada também poderá subordinar-se a essa aprovação $0^{22}$, que, neste último caso, apenas se diferencia do primeiro por anteceder à vigência do ato.

A distinção entre o decreto-lei e a lei não atinge o seu aspecto material (a natureza intrínseca do ato, o que ele é em sua essência, ontologicamente, segundo a sua eficácia e hierarquia, sendo apenas uma questão formal (em razão do órgão de que emanam : um, do Executivo; o outro, do Legislativo).

Nem mesmo no que tange à sua elaboração se estabelecerá uma distinção permanente, pois, se é certo que o decreto-lei pode ser um ato simples, isto é, produzido por uma só vontade, a lei também poderá, no nosso Direito, revestir tal forma ${ }^{23}$.

são De um modo geral, porém, tanto o decreto-lei quanto a lei vo atos complexos ${ }^{24}$, isto é, para sua formação concorrem várias vontades com "o mesmo objetivo e que se harmonizam numa só, que se divulga.

\footnotetext{
22. Id. art. 54, parágrafo único.

23. A lei, como o decreto-lei, pode provir de um ato simples, em duas hipóteses: a) no caso em que seja elaborado o projeto por uma só pessoa do Executivo e este, através do seu Chefe, o encaminha ao Congresso Nacional, com solicitaçāo de prazo (Const. Federal, art. art. 51 , caput, e $\S 2 .^{\circ}$ ), sendo o projeto tal como enviado promulgado como lei, por falta de deliberação nos prazos (Const., art. $51, \S 3 .^{\circ}$ ); b) quando, na delegação legislativa ao Presidente da República, é elaborada a lei nas mesmas condições previstas na alínea anterior para o decreto-lei, isto é, quando uma só vontade formou a lei.

Segundo LUCIFREDI (Atti Complessi, in Novissimo Digesto Italiano, 3.• ed., Turim, 1957, tomo II, vol. I, ps. 1500 e 1501, apud MANOEL GONÇALVES FERREIRA FILHO, Comentários à Constituiçãao Brasileira, Saraiva, São Paulo, 1974, vol. II, p. 10), há ato complexo sempre que "duas ou mais vontades homogêneas tendentes a um mesmo fim se fundem numa só vontade declarada, idônea a produzir determinados efeitos jurídicos que não poderiam de modo algum produzir se faltasse tal concurso de vontades"
} 
12. A rejeição do decreto-lei pelo Congresso Nacional tem por efeito a revogação ex nunc, assegurando-se-Ihe plena vigência desde sua entrada em vigor até a data da rejeição, quanco então voltam a viger as normas que porventura tenham sido revogadas pelo ato rejeitado. Nesta hipótese, a lei revogada se restaura por ter perdido a vigência a lei revogada ${ }^{25}$. Com essa disposição do $\S 2 .^{\circ}$ do art. 55 , introduzido pela Emenda Constitucional n..$^{1}$, de 1969 , terminou a divergência sobre se os efeitos do ato rejeitado seriam ou não nulos, para se conceituarem como tão-somente revogados ex nunc, isto é, a partir da vigência da rejeição ${ }^{26} \mathrm{e}^{27}$.

13. A origem do decreto-lei, tal como previsto na Constituição em vigor, está nas ordinanze di necessità do direito italiano, quando, para satisfazer exigências imprevistas e imprevisíveis, cujo atendimento é imprescindível à conservação do Estado, se autoriza diretamente o Chefe do Governo a baixar atos com força de lei formal e material, ainda que sujeitos à ratificação a posteriori do Legislativo.

Igualmente aparece essa autorização excepcional legislativa na Constituição em vigor da República Federal da Alemanha, que prevê, no seu art. 81, o "estado de necessidade legislativa"28,

14. A competência legislativa originária expressa deferida constitucionalmente ao Presidente da República para disci-

25. Cf. Lei de Introduçăo ao Código Civil, art. $2 .^{\circ}, \S 3$.

26. PONTES DE MIRANDA consigna a descontituição de eficácia ex tunc, como se nulos fos sem os efeitos, mesmo em seus comentários já com a redação dada pela Emenda Constitu cional n.० 1, de 1969, mas é evidente que, por equivoco, foram reproduzidos, como comen tários ao artigo, o que se continha nas notas referentes à redaçăo primitiva (art. 58), hå vendo assim inúmeras impropriedades e omissōes, quando o texto legal é o da Emenda Cons titucional $n \cdot 0^{\circ}$ 1, mas os comentários săo feitos ao texto primitivo, grandemente alterado ( $C$ f. Comentários à Constituição de 1967, 2.0 ediçăo. Revista dos Tribunais, Săo Paulo, julho de de 1970 , tomo III, ps. 160 e 161 .

27. Esclareça-se o Congresso Nacional só poderia rejeitar o decreto-lei no seu todo, não o po dendo fazer em parte, pois tal infringiria o disposto no art. $55, \S 1 . \circ$, que não permite emenda, e a rejeiçăo parcial nisso importaria (Cf., no mesmo sentido, PONTES DE MIRAN DA, Comentários, cits., tomo III, p. 161).

28. Cf. MANUEL GONÇALVES FERREIRA FILHO, Do Processo Legislativo, cit., n.॰os 103 a 105 no excelente resumo que faz sobre a matéria

Sobre os decretos-leis no direito italiano, Cf. GINO SOLAZZI I Decreti-legge, in Com mentário Sistemático alla Constituzione Italiana, dirigido por Piero Calamandrei e Alessan dro Levi, Florença, 1950, vol. II, ps. 97 a 103 
Plinar certas matérias através de decreto-lei tem como pressurosto de sua autorização a urgência e o interesse público relevante 29 , limitada à exigência de que daí não decorra aumento de despesa.

Se o interesse público relevante é muito subjetivo, não havendo como controlá-lo, ficando à livre discrição do Presidente da República, o mesmo não ocorre com a urgência, que pode ser externamente apreciada, sujeitando-se assim ao controle jurisdicional. 30

Como ensina GERALDO ATALIBA, só se concretiza a urgência "quando a exigência de ordenação não possa tolerar sem dano ao interesse público - demora superior a quarenta dias", ou se ache o Congresso em recesso ${ }^{31}$.

É que, permitindo a Constituição o processo legislativo acelerado, cujo prazo máximo de deliberação é de quarenta dias (art. $51, \S 2 .^{\circ}$ ), só se tem por caracterizada a urgência se houver necessidade de uma disciplinação imediata, que não possa aguardar o decurso daquele prazo, ou se for excessiva delonga a espera do término do recesso do Congresso.

15. Verificada a urgência, não há como impugnar o decreto-lej32 que discipline qualquer das matérias indicadas nos números do art. 55, e somente elas, condicionando-se tudo a que não haja aumento de despesa.

Por aumento de despesa, evidentemente, não se há de entender que seria defeso ao Presidente da República baixar normas

29. "Para conciliar interesse público relevante e urgência, uma exegese há de prevalecer. Consiste em ver no interesse público relevante e na urgência duas condições a serem realizadas necessariamente para que caiba a ediçăo do decreto-lei. A conjunção ou equivale, como ocorre tantas vezes na linguagem jurídica, a $e^{n}$ (MANUEL GONÇALVES FERREIRA FILHO. Comentários cits., vol. II, p. 44).

30. No mesmo sentido do texto, MANUEL GONÇALVES FERREIRA FILHO Comentários cits., vol. II. p. 44. Cf., também, GERALDO ATALIBA, ob. cit., ps. 31 a 33.

Em sentido contrário, entretanto, há acórdão do Supremo Tribunal Federal, no Rec. Extraord.

n.० 62.731-GB, relator o Min. ALIOMAR BALEEIRO, in R.T4J., vol. 45, ps. 559 e segs. Esse aspec-

to todavia, fol abordado incidentamente, năo nos parecendo apoiado na melhor doutrina.

31. Ob. cit., ps. 32 e 33

32. Entenda-se a Impugnaçăo como extra-Legislativo, pois este tem competência discricionária para rejeitá-lo no prazo estabelecido no $\S 1.0$ do art. 55 . 
que produzissem gastos públicos, mas apenas que essa despesa, que o ato em muitos casos determinará, se comporte nas dotações orçamentárias, sem que haja necessidade de suplementação. Do contrário, como se conciliaria a restrição com a autorização para disciplinar por decreto-lei a "criação de cargos públicos e fixação de vencimentos" (art. 55, n. ${ }^{\circ}$ III)? Não poderia, como é curial, haver criação de cargos e fixação de vencimentos sem que 0 ato produzisse gastos ${ }^{33} \ldots$

16. Essa competência legislativa originária expressa, dada a sua natureza excepcional, limita-se às matérias indicadas nos três números do artigo, não comportando interpretação extensiva ou analógica.

A edição de ato que contenha matéria diversa da constante da autorização excepcional não se convalida pela aprovação tácita ou expressa do Congresso Nacional, podendo ser-lhe negada eficácia ${ }^{34}$, por inconstitucionalidade, através do competente pronunciamento do Poder Judiciário ${ }^{35}$.

17. A primeira matéria contemplada na Constituição é a segurança nacional. E, por esta, se há de entender, consoante jurisprudência do nosso mais alto Pretório, não vagamente, como algo indefinido e plástico, mas o que concerne "à defesa da integridade do território, independência, paz e sobrevivência do País, suas instituições e valores materiais ou morais, contra ameaças externas e internas. Em duas palavras, contra a guerra externa ou intestina, esteja ela travada e efetiva ou fermente ainda em estado potencial próximo ou remoto ${ }^{36 "}$ ".

18. A segunda das matérias arroladas ("finanças públicas, inclusive normas tributárias") aparecia na primitiva redação apenas na primeira parte (finanças públicas), o que determinou uma série de divergências, entendendo GERALDO ATALIBA, com inegável acerto, que só abrangia o direito financeiro, excluindose assim o direito tributário ${ }^{37}$. Com o acréscimo introduzido pela

33. No mesmo sentido, MANUEL GONÇALVES FERREIRA FILHO, Comentários, cits. vol. II, p. 49

34. Cf. GERALDO ATAlibA, ob. cit. ps. 42 e 43 .

35. Cf. acórdăo citado na nota 30 , supra

36. Mesmo acórdăo, revista e vol. cits., p. 564

37. Ob. cit., ps. 64 a 66 .

R. Serv, públ., Brasília, 109 (2) abr./jun. 1974 
Emenda Constitucional n. ${ }^{\circ}$, de 1969 , não há mais dúvidas sobre a autorização de editar normas tributárias, além das de direito financeiro.

A competência de baixar normas de direito tributário abrangeria também, a de instituir ou aumentar tributo?

A matéria é suscetivel de divergência, entendendo uns ${ }^{38}$, entre os quais nos encontramos, que a instituição ou o aumento cie um tributo só pode ocorrer por força de lei, na forma do art. 153 , § 29 , da Constituição, sendo a palavra lei, aí, interpretada em sentido estrito, não se substituindo por ato legislativo de modo genérico, com o que se excluiria o decreto-lei. De fato, estabelecer normas tributárias não é o mesmo que instituir ou aumentar tributos. Por estabelecer normas tributárias terá de entender-se apenas a disciplinação do direito tributário, mas não a criação ou majoração de tributos.

19. Quanto à terceira matéria (criação de cargos públicos e fixação de vencimentos), não oferece qualquer dificuldade, devendo esclarecer-se, de logo, que aí apenas se incluem: a) a criação de cargos públicos e respectiva fixação de vencimentos, o que raramente poderá ocorrer, por ser pouco provável que haja uma necessidade tão premente dessa criação que não se possa aguardar ou o término do recesso, ou o decurso do processo legislativo abreviado (quarenta dias - art. $51, \S 2 .^{\circ}$ ); b) a majoração de vencimentos de cargos já existentes, em geral em decorrência da desvalorização da moeda, sempre urgente e que vem coincidindo com o recesso do Congresso.

Mas, a pretexto de criação de cargos ou de fixação de vencimentos, nenhuma outra norma de natureza diversa, mesmo conexa com a fixação de vencimentos, que requeira ato legislativo, poderá ser baixada por decreto-lei.

20. Embora de caráter excepcional e restrita a determinadas matérias, além de sujeição ao placet do Congresso (deCreto-lei), ou incidentalmente (projeto de lei do Presidente da República promulgado como lei por omissão deliberativa do Congresso no prazo estipulado), não há negar que cabe ao Chefe do

38. PONTES DE MIRANDA, Comentários à Constituiçăo Federal de 1967, Revista dos Tribunais S. Paulo, 1967, Tomo II, p. 161, apud MANUEL GONÇALVES FERREIRA FILHO, Comentários, cits., vol, II, p. 48. 
Governo, constitucionalmente, atividade legislativa originária, além da derivada, oriunda de delegação legislativa.

Trata-se de um fenômeno universal, que tem condicionado também os países em que a democracia é exercida com mais eficiência, quando não é possível aos parlamentos, materialmente, acompanhar a evolução tecnológica moderna, redundando assim num alargamento de atribuições a conferir-se ao Executivo. Não há por que acoimar essa evolução de retrocesso democrático. É apenas uma questão de perspectiva, em que ou se segue o desenvolvimento científico natural, moldando as instituições às necessidades que vão surgindo, ou se procura deter o tempo, $e$ as instituições obsoletas passam a fazer jus a um tombamento no patrimônio histórico e a se arquivarem nos museus. A Política é uma ciência dinâmica, que está em constante transformação para adaptar-se aos princípios científicos que a informam.

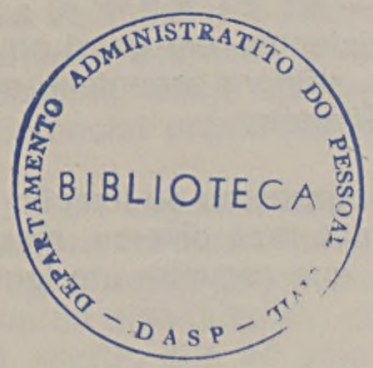

